Presence of human papillomavirus in genital tumours. $f$ Invest Dermato

3 Schneider PS, Krumholz BA, Topp WC, Steinberg BM, Abramson AL. Molecular heterogeneity of female genital wart (condylomata acuminata papillomaviruses. Int $\mathcal{f}$ Gynecol Pathol 1984;2:329-36.

4 Gross G, Ikenberg H, Gissmann L, Hagedorn M. Papillomavirus infection of the anogenital region: correlation between histology, clinical picture and virus type: proposal of a new nomenclature. I Invest Dermatol 1985; 85:147-52.

5 de Villiers E-M, Gissman L, zur Hausen H. Molecular cloning of viral DNA from human genital warts. 7 Virol 1981;40:932-5.

6 Orth G, Favre $M$, Croissant $O$. Characterization of a new type of human papillomavirus that causes skin warts. I Virol 1977;24:108-20.

7 Gissmann L, Pfister H, zur Hausen H. Human papilloma viruses (HPV): characterization of four different isolates. V'irology 1977;76:569-80.

8 Goldenring JM. Condylomata acuminata in the pediatric patient. $f \mathrm{rol}$ 1987;138:1259-60.

9 Bender ME. New concepts of condyloma acuminata in children. Arch Dermatol 986;122:1121-4

10 Goldenring JM. Condylomata acuminata in the evaluation of child sexua abuse. Arch Dermatol 1987;123:1265-6.

11 Oriel JD. Anogenital papillomavirus infection in children. $\mathrm{Br} \mathrm{Med} f$ 1988;296: 1484-5

12 Shelton TB, Jerkins GR, Noe HN. Condylomata acuminata in the pediatric patient. F Crol 1986;135:548-9.

13 Vallejos H, Del Mistro A, Kleinhaus S, Braunstein JD, Halwer M, Koss LG. Characterization of human papilloma virus types in condylomata acuminat in children by in situ hybridization. Lab Invest 1987:56:611-5.

14 Rock B, Naghashfar Z, Barnett N, Buscema J, Woodruff D J, Shah K. Genital tract papillomavirus infection in children. Arch Dermatol 1986;122:1129-32.

15 Benton EC, MacKinlay GA, Barr BB, Smith IW. Characterization of human papillomavirus DNA from genital warts in children. Br $\mathcal{J}$ Dermatol 1989;121(suppl 34):36.
16 Fleming $\mathrm{KA}$, Venning $\mathrm{V}$, Evans $\mathrm{M}$. DNA typing of genital warts and diagnosis of sexual abuse of children. Lancet 1987 ;ii:454.

17 Androphy EJ. Human papillomavirus: current concepts. Arch Dermatol 1989:125:683-5

18 Burns J, Redfern DRM, Esiri MM, McGee JO'D. Human and viral gene detection in routine paraffin embedded tissue by in situ hybridisation with biotinylated probes: viral localisation in herpes encephalitis. $\mathcal{f}$ Clin Patho 1986;39:1066-73

19 Porter HJ, Khong TY, Evans MF, Chan VT-W, Fleming KA. Parvovirus as a cause of hydrops fetalis: detection by in situ DNA hybridisation. $f$ Clin Pathol 1988;41:381-3.

20 Burns J, Graham AK, McGee JO'D. Non-isotopic detection of in situ nucleic acid in cervix: an updated protocol. 7 Clin Pathol 1988;41:897-9.

21 Burns J, Chan VT-W, Jonasson JA, Fleming KA, Taylor S, McGee JO'D. Sensitive system for visualising biotinylated DNA probes in situ: rapid sex determination of intact cells. F Clin Pathol 1985;38:1085-92.

22 Herrington CS, Graham AK, Burns J, McGee JO'D. The investigation of double infection of condylomata acuminata by human papillomaviruses using a double labelling technique. I Pathol 1989;157:171A

23 Bennett RS, Powell KR. Human papillomaviruses: associations between laryngeal papillomas and genital warts. Pediatr Infect Dis $\mathcal{f}$ 1987;6:229-32.

24 Cohen SR, Geller KA, Seltzer S, Thompson JW. Papilloma of the larynx and tracheobronchial tree in children: a retrospective study. Ann Otol Rhinol Laryngol 1980;89:487-503.

25 Gissmann L, Wolnik L, Ikenberg H, et al. Human papillomavirus types 6 and 11 DNA sequences in genital and laryngeal papiliomas and in some cervical cancers. Proc Natl Acad Sci USA 1983;80:560-3.

26 Krzyzek RA, Watts SL, Andersen DL, Faras AJ, Pass F. Anogenital warts contain several distinct species of Human Papillomavirus. F Virol 1980; 36:236-44.

(Accepted 9 March 1990)

\title{
Control of defecation in patients with spinal injuries by stimulation of sacral anterior nerve roots
}

\author{
R P MacDonagh, W M Sun, R Smallwood, D Forster, N W Read
}

Spinal Injuries Unit, Lodge Moor Hospital, Sheffield S10 4LH

R MacDonagh, FRCS, Medical Research Council research fellow

\section{Subdepartment of}

Gastrointestinal

Physiology and Nutrition,

Department of Medical

Physics, and Department of

Neurosurgery, Royal

Hallamshire Hospital,

Sheffield

W M Sun, MB, research fellow

R Smallwood, FIEE,

consultant medical physicist

D Forster, FRCS, consultant neurosurgeon

N W Read, FRCP, professor

Correspondence to: $\mathrm{Mr}$ MacDonagh.

BrMed f 1990;300:1494-7

\section{Abstract}

Objective-To observe the effects of stimulation of the sacral anterior roots on anorectal and low colonic pressures and to programme implanted stimulators to produce defecation.

Design-Prospective study of 12 consecutive patients.

Setting-Spinal injuries unit and university gastrointestinal physiology department.

Patients - 12 Patients with complete supraconal spinal cord lesions. Their injuries had been sustained at least two years before the study.

Interventions-A Brindley-Finetech intradural sacral anterior root stimulator was implanted in all patients. Three months postoperatively the stimulator settings were adusted after measurement of simultaneous anorectal and low colonic pressures.

Main outcome measures-Full defecation.

Results-Six patients achieved complete rectal evacuation of faeces using the implant and subsequently did not require manual help for defecation. For all but one of the patients the total time taken to complete defecation was reduced, and all were free from constipation, the most prevalent gastrointestinal symptom in patients with spinal injuries.

Conclusions-Sacral anterior root stimulators can be programmed to achieve complete unassisted defecation and can considerably improve the quality of life of patients with spinal injuries.

\section{Introduction}

Spinal cord injuries often occur in fairly young people, who have the prospect of an almost normal life expectancy but a considerably impaired quality of life. These patients not only experience severe dysfunction of voluntary movement but also have impaired bladder, bowel, and sexual function.

Urinary problems in patients with spinal cord injuries have been extensively studied, and with the advent of intermittent self catheterisation, ${ }^{1}$ electrical stimulation of the bladder, ${ }^{2}$ and advances in diagnostic techniques considerable improvements have been made in managing lower urinary tract and renal function. In contrast, the management of bowel disorders and, in particular, the intractable constipation that is so common in these patients has remained essentially unchanged over the past two decades.

The first sacral anterior root stimulator was implanted in a patient with a spinal injury in $1976 .{ }^{34}$ Since then roughly 300 patients throughout Europe have had such devices implanted, with much success in managing the neurogenic bladder. The stimulator was initially developed to improve bladder emptying, ${ }^{25}$ but as the parasympathetic and somatic nerves that supply the distal colon, anorectum, and anal sphincter are all derived from the same sacral spinal roots that are used for electromicturition it seemed likely that the stimulator could also be used to induce defecation in paraplegic patients. Little has been reported regarding the action of the stimulator on colorectal motility, ${ }^{6}$ and there are few reports of full evacuation with this technique. ${ }^{78}$

We report clinical and manometric data on 12 consecutive patients with spinal injuries who had sacral anterior root stimulators implanted.

\section{Patients and methods}

PATIENTS

We studied 12 consecutive patients (three women and nine men aged 21-49 (mean age 33)). All had received traumatic spinal injuries that had resulted in complete supraconal cord lesions (10 thoracic, two cervical). Sacral anterior root stimulators were not implanted in patients until at least two years after their injuries occurred to allow for any neurological recovery. The time since implantation ranged from three months to six years (mean time 26.3 months), and all patients included in the study were using the stimulator effectively to empty the bladder.

After surgery for implantation we assessed evidence 
of damage to the anterior nerve root. Ten patients had normal function in all three pairs of roots, but the left side of the S4 root in one patient and the S2 root bilaterally in another failed to produce normal responses of the pelvic floor and leg muscles. All but three patients had had deafferentation of the sacral posterior nerve roots (S2 to $S 4$ ) at the time of implantation to produce detrusor areflexia and hence urinary continence.

\section{QUESTIONNÄIRE}

Immediately before implantation and then after the stimulator had been programmed for defecation we asked patients to complete a questionnaire detailing every aspect of their bowel habit. Particular emphasis was placed on the method they used to achieve a bowel action, the frequency of defecation, and the time taken to complete each evacuation by whatever method was appropriate.

\section{SACRAL ANTERIOR ROOT STIMULATORS}

All the patients had had a Brindley-Finetech sacral anterior root stimulator implanted as previously described, ${ }^{8}$ although the method varied in the first three patients as their posterior nerve roots were not divided. The implants were positioned intradurally and connected to a receiver unit placed subcutaneously on the lower chest wall by multiconductor cables coated with silicone. ${ }^{9}$ To apply stimulation the patient held a transmitter immediately over the implanted receiver and switched on a small hand held unit. The receiver contained simple passive circuits that were activated by pulse modulated radiofrequency waves generated by the transmitter block. ${ }^{1011}$ The pulse frequency, amplitude, and width were all adjustable and a single pair of roots or any combination of the three pairs (S2, S3, or S4) could be stimulated.

\section{SETTING PARAMETERS FOR STIMULATION}

We studied all patients at least three months postoperatively to allow maximum recovery of any damaged anterior nerve roots. We observed the response to stimulation of the sacral roots by measuring anorectal and low colonic pressures at approximately $0 \cdot 5,1,2,8$, 15 , and $18 \mathrm{~cm}$ from the anal verge. ${ }^{12}$ No formal bowel preparation was given, although the patients were instructed to defecate in their normal way on the morning of the study.

The principle behind using the stimulator to produce micturition is that the smooth muscle of the detrusor relaxes more slowly than the striated muscle of the urethral sphincter after stimulation is stopped, and for a short period of time, therefore, a gradient of pressure exists and micturition can occur. ${ }^{2}$ If the stimulus is turned on and off in a regular pattern, the gradient occurs intermittently, and the patient micturates in bursts. We used the same principle to obtain the maximum possible rectal and low colonic pressures during anal relaxation, thus producing an intermittent gradient of pressure from the rectum to the anal canal, allowing defecation to occur.

We determined the optimum stimulus parameters with an in house computerised system, which exactly reproduced the electrical output of the BrindleyFinetech stimulator. This allowed us to vary the stimulation parameters of each nerve root rapidly and accurately and select individual roots or combinations of roots.

For each patient we followed a standard protocol. Each individual pair of nerve roots was stimulated in turn (S2, S3, then S4), and the effect on the lower colonic and anorectal pressure observed. Combinations of the three nerve roots were then stimulated, using S3 and S4 first, followed by S2, S3, and S4 together. The initial strength of stimulus was the same as that used for electromicturition but with an intermittent pulse of 10 seconds on and 20 seconds off. ${ }^{8}$ The strength of stimulation could be varied by changing the pulse frequency (range 10-20 ms), the pulse amplitude (range approximately $10-40 \mathrm{~V}$ ), or the pulse width (range 100-600 $\mu$ s). The available range of on and off periods of stimulation was one second to three minutes. The stimulation strength and intermittency were varied according to the lower colonic and anorectal responses. Unfortunately, we could use only parameters equal to or less than those used for bladder emptying to minimise the possibility of generating abnormally high detrusor pressures, which in the long term can compromise upper urinary tract function. Intervals of at least five minutes were allowed between each burst of pulses to allow smooth muscle fatigue to recover.

Thus by a process of trial and error we selected for each patient the most effective nerve root or roots and the optimum strength and intermittency of stimulus to achieve increased colonic activity with the maximum rectoanal pressure gradient. We then tested these parameters using a simulated stool made from porridge paste $(100 \mathrm{ml}$ warm water, $30 \mathrm{~g}$ oats) which has a similar consistency to normal faeces. The porridge paste was injected into the rectum with a bladder syringe and the effect of stimulation on evacuation observed. The parameters could still be adjusted at this stage to optimise defecation.

Once we were satisfied with the stimulator settings the patient was discharged with instructions to use the implant while sitting on the toilet and, if full defecation did not occur within 10 minutes, to perform manual evacuation of the remaining rectal contents. We suggested that each patient see how the stimulator affected his or her bowel habit and then adopt whatever method of defecation was appropriate.

\section{Results}

\section{MANOMETRIC DATA AND STIMULATION PARAMETERS}

Stimulation of individual nerve roots produced a wide range of manometric responses. In general, however, stimulating the $S 2$ root produced low pressure colorectal activity whereas stimulating S3, and to a lesser extent $\mathrm{S} 4$, produced colorectal contraction. Stimulating $\mathrm{S} 4$ gave the maximum pressure response in the anal canal, almost certainly because of its action on the external anal sphincter.

Rectosigmoid contraction and associated anal relaxation were best achieved by simultaneously stimulating all three pairs of anterior roots in nine patients (fig 1), by stimulating S3 alone in one patient, and by stimulating $\mathrm{S} 3$ and $\mathrm{S} 4$ together in another patient. In one patient stimulating $\mathrm{S} 3$ resulted in low colonic activity in excess of $5.9 \mathrm{kPa}$ but no rectal activity and stimulating $\mathrm{S} 4$ produced a good rectal contraction with anal relaxation (fig 2 ). This patient achieved full evacuation of faeces by stimulating S3 followed by $S 4$ but not by stimulating either root alone.

Varying the strength of stimulation had a graded effect on the rectal smooth muscle similar to that seen with the detrusor ${ }^{4}$ : rectal pressure increased progressively as the stimulus was increased. The strength of stimulus required to produce the optimum manometric response varied considerably among the patients within the range of pressures that were not damaging to the detrusor. The maximum pulse amplitude and frequency $(40 \mathrm{~V}, 20 \mathrm{~ms})$ were used by six patients, and in all but one the optimum pulse width was $200 \mu \mathrm{s}$.

Continuous stimulation increased rectal pressure but did not produce evacuation owing to fatigue of the rectal smooth muscle and prolonged activity of the striated muscle of the anal sphincter. Thus all patients used intermittent stimulation. The "on" time varied 
from 4.5 to $15 \mathrm{~s}$ (mean $9 \mathrm{~s}$ ) and was determined by the rate of increase in rectal pressure during stimulation. The rectal smooth muscle differed from the detrusor muscle in that it was slower to respond to stimulation, taking up to $4.5 \mathrm{~s}$ to begin to contract. After the stimulus was stopped the rectum continued to contract for a short period, during which time the pressure in the anal canal fell. The duration of the "off" time $(6-30 \mathrm{~s}$, mean $14 \cdot 45)$ depended on when the rectal pressure returned to or approached its basal value.

When setting the implant to produce optimum emptying of the bladder it is necessary to wait about three minutes between each burst of impulses to allow full recovery of the smooth muscle of the detrusor. ${ }^{5}$ The rectal muscle also fatigued but took five minutes or more to recover enough to produce an indentical response with the same nerve roots and strengths of stimulus.

\section{PORRIDGE STOOL TEST}

Nine patients evacuated the porridge paste stool either partially (one patient) or completely (eight patients); six of them were subsequently able to defecate using the stimulator alone.

Some patients required further adjustments to the stimulator after the initial porridge stool test, and two more patients achieved evacuation of the simulated stool after this. None of the patients who could not evacuate the porridge stool were subsequently able to defecate.

\section{DEFECATION}

Of the 12 patients tested, five achieved complete evacuation of faeces using the stimulator alone,

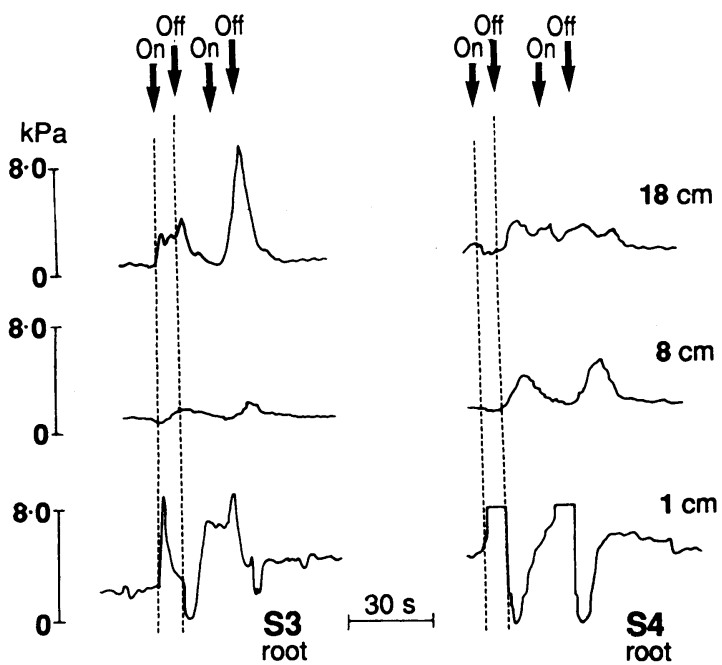

FIG 1-Tracings of anal canal, rectal, and low colonic pressures in paraplegic patient (case 2), showing coordinated anal relaxation and rectosigmoid contraction during the "off" periods of intermittent simultaneous stimulation of S2, S3, and S4 anterior roots. Measurements were taken 18,8 , and $1 \mathrm{~cm}$ from anal verge and one evacuated the rectum completely using the stimulator and straining (table).

Before implantation the mean frequency of defecation was $5 \cdot 5$ times/week, with nine patients opening their bowels every other day. After implantation 10

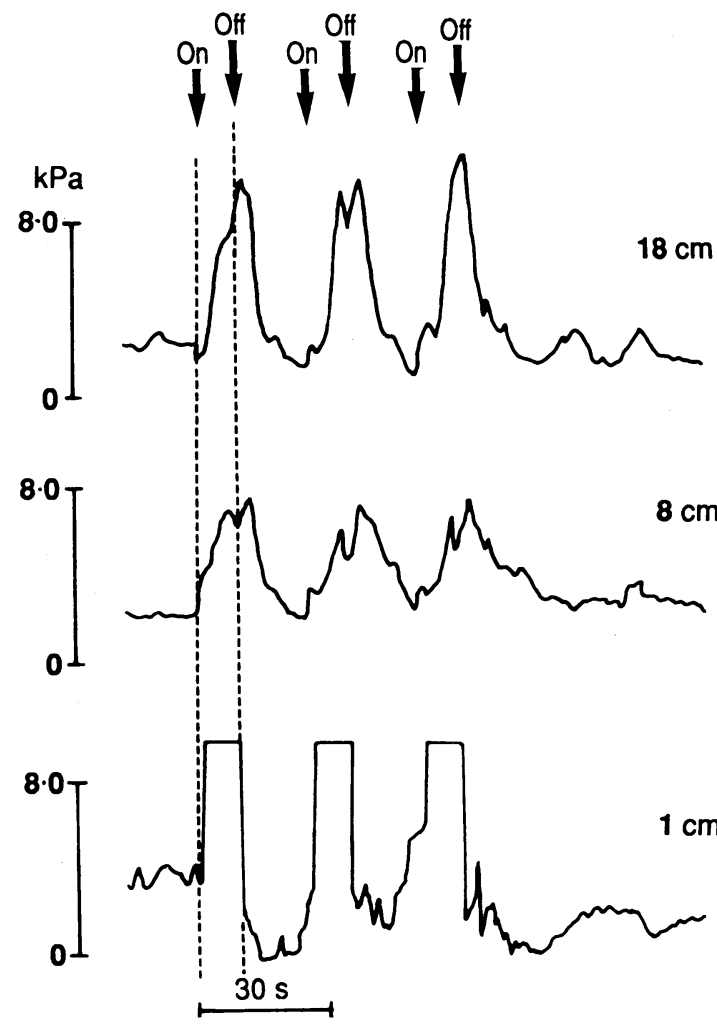

FIG 2-Tracings of anal canal, rectal, and low colonic pressures in paraplegic patient (case 9), showing different responses to stimulation of $S 3$ and $S 4$ nerve roots. Measurements were taken 18,8 , and $1 \mathrm{~cm}$ from anal verge

patients defecated daily (mean frequency 8.3 times/ week). In all patients except one the time taken to defecate was shortened by using the stimulator. Even taking into account the increased frequency, the mean time spent defecating each week was significantly less after implantation than before $(28.9 \mathrm{~min} /$ week $v 150.5$ $\mathrm{min} /$ week; $\mathrm{p}<0.005)$. Those patients not able to defecate using the stimulator alone had to perform manual evacuation: because deafferentation abolished reflex defecation, preventing the use of suppositories, laxatives, or anal digitation.

\section{CONSTIPATION}

Eleven of the 12 patients reported at least one episode of constipation requiring prolonged use of oral laxatives, bowel enemas, or hospital admission in the two years before implantation. We had no reports of constipation in any patient in this study after the stimulator was implanted.

Method of defecation used by patients with spinal injuries before and after implantation of sacral anterior root stimulator

\begin{tabular}{|c|c|c|c|c|}
\hline \multirow[b]{2}{*}{ Case No } & \multicolumn{2}{|c|}{ Before implantation } & \multicolumn{2}{|c|}{ After implantation } \\
\hline & Method of defecation & $\begin{array}{l}\text { Time spent defecating } \\
\text { each week (min) }\end{array}$ & Method of defecation & $\begin{array}{l}\text { Time spent defecating } \\
\text { each week (min) }\end{array}$ \\
\hline 1 & Reflex and manual evacuation & 30 & Stimulator and straining & 24 \\
\hline 2 & Reflex and manual evacuation & 120 & Stimulator & 21 \\
\hline 3 & Manual evacuation & 225 & Stimulator and manual evacuation & 50 \\
\hline 4 & Reflex and straining & 370 & Stimulator and manual evacuation & 80 \\
\hline 5 & Manual evacuation & 44 & Stimulator and manual evacuation & 21 \\
\hline 6 & Manual evacuation & 50 & Stimulator & 40 \\
\hline 7 & Reflex and manual evacuation & 71 & Stimulator and manual evacuation & 21 \\
\hline 8 & Reflex and manual evacuation & 220 & Stimulator and manual evacuation & 14 \\
\hline 9 & Reflex & 315 & Stimulator & 14 \\
\hline 10 & Reflex & 100 & Stimulator & 14 \\
\hline 11 & Reflex & 140 & Stimulator & 21 \\
\hline 12 & Reflex & 122 & Stimulator and manual evacuation & 25 \\
\hline
\end{tabular}


COMPLICATIONS

The only postoperative complication in this series was leakage of cerebrospinal fluid along the implanted cables to the receiver site on the chest wall. This occurred in two patients, and both were managed conservatively and successfully by rest, flat in bed, for two weeks.

\section{Discussion}

Six of the 12 patients were able to use the sacral anterior root stimulator to defecate without needing self stimulation of the rectum or manual evacuation. For all patients the time spent defecating each week fell significantly and, perhaps more importantly, constipation, which is common after spinal injury, was eradicated.

Patients with supraconal spinal cord lesions have an intact conus medullaris and canda equina and hence normal sacral spinal reflexes. Consequently, these patients not only retain reflex erectile and detrusor activity but also can defecate reflexly by rectal stimulation with suppositories or stimulant solutions. Deafferentation of the sacral roots is done during implantation of the stimulator to treat urinary incontinence, and patients are no longer able to defecate reflexly and therefore have to perform manual evacuation. The sacral anterior root stimulator seems to deliver faeces to the rectum and patients who cannot defecate using the implant alone find manual evacuation more acceptable because it is usually both quicker and more controllable than the reflex method of evacuation.

The porridge stool test predicted most of the patients who would be able to defecate using the stimulator with chosen parameters and allowed final adjustments of the parameters to be made so that the chance of future defecation was optimised. Unfortunately, however, a positive test result was not a guarantee of successful defecation: three patients who evacuated the artificial stool were later unable to repeat this with normal faeces.

We found that setting the sacral anterior root stimulator for effective defecation is not simply a matter of using a standard set of parameters as has been suggested. ${ }^{8}$ Recordings of lower colonic and anorectal pressures showed that responses to stimulation of both single and combinations of nerve roots vary. This agrees with the results of Varma $e t a^{t}$ and emphasises the importance of manometric recording during stimulation to optimise the possibility of future defecation.

We used an $18 \mathrm{~cm}$ manometry tube to measure anorectal and colonic pressure at six sites. In the future we plan to simplify this technique by using an $8 \mathrm{~cm}$ tube with one anal and one rectal pressure channel. If the results are acceptable it will be easy to modify our existing cystometry equipment so that bladder and bowel functions can be programmed at the same time. The ability of the sacral anterior root stimulator to produce defecation together with its effect on bladder and erectile function can considerably improve the quality of life for patients with spinal injuries.

The study was funded by the Medical Research Council.

I Lapides J. Dionko A, Silbent S. Clean intermintent seff cathererisation in the treatment of urinary tract disease. $7 \mathrm{Crud}$ 1972;49.5236.

2 Brindky GS. Emptying the beadder by stimubting sacral ventral routs J Phusiod (Paris) 1973;237:15-6.

Brindter GS, Polker CE, Rushton DN. Sacral anterior root stimulation for bbaddet conturl in paraplegies. Pareplegio 1982;20:365-81.

4 Cardozo L., Krishnan KR, PolkerCE, Rushton DN, Brindkr GS. Urodtnamiv

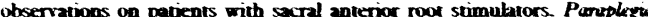
1984:22:201-9.

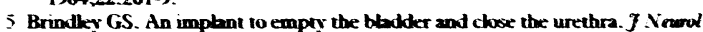

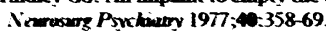

Varma JS, Binnie NR, Smith AN, Creasy G, Ectmond P. Differencial effects of sacral anterior rook stimutation on anal sphincter and colorectal motitiv in spinally injured man. Bo $\mathcal{f}$ Swg 1986;73:478-82.

7 Brindley GS. The actions of the perasymperthetic and sympothetic nerves in human micturition, erection and semimal cmission and their restoration in paraplegic patients by implanted dectrical stimubarors: the Ferrier lecture 1986. Proc R Soc Lond [Bsol] 1988:235:111-20.

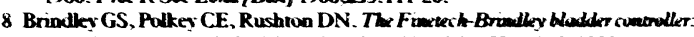

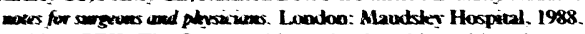

9 Donalkon PEK. The Cooper cable: an implaniable multiconiluctur cable for

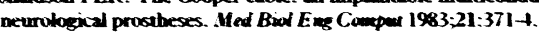

10 Brimitky GS. Transmission of etectrical stimuli aloag many independent channets throwgh a fairts small area of intact skin. I Phussid (Pans 1964:177:+16.

11 Ivall T. Ratioactivated imptant for beadder cuatrol. Wircless Workd 1984 $J \ln \rightarrow 1+$

12 Sun WM. Read NW, Donnelly TC. Impaired intermal anal sphincter in a

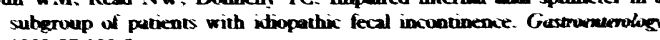
$1099-97: 1305$.

Accoperd 3 Apri' 1900
Royal Berkshire Hospital, Reading

Sally A Buckley, FCOPHTH, serior house officer

Br Med 7 1990:300:1497-8

\section{Survey of patients taking topical medication at their first presentation to eye casualty}

\section{Sally A Buckley}

A large proportion of patients taking topical medication at their first presentation to eye casualty at the Royal Berkshire Hospital seemed to be suffering from adverse reactions to their drops. To assess the size of the problem I performed a prospective study.

\section{Patients, methods, and results}

From 15 November 1988 to 15 February 1989, 2186 new patients attended the eye casualty department, of whom 145 were already taking topical medication. These patients were asked to complete a questionnaire designed (on a yes/no basis) to elicit the original symptoms, the symptoms on presentation to the casualty department, eye medication, and length of treatment. When they had completed the questionnaire the casualty officer assessed the presenting complaint.

The table shows that toxic and allergic reactions to eye drops comprised the largest group of diagnoses (40) among the 145 patients taking drops at presentation. Toxic reactions were characterised by persistent or worsening follicular conjunctivitis and corneal punctate epitheliopathy. Allergic reactions were mainly due to type IV hypersensitivity reactions - that is, contact dermatitis - characterised by pruritus with red puffy lids and conjunctival papillary reaction. A trial of 48 hours without treatment produced considerable symptomatic improvement in both groups.

Fifteen different drops were implicated, chloram-

Diagmoses made in eye casualyy department in patients already taking ove drops, showing mombers of patients is each group and nombers using chloromphemicol on presentation

\begin{tabular}{|c|c|c|}
\hline Dragnosis & $\begin{array}{c}\text { No } \\
\text { of } \\
\text { patients }\end{array}$ & $\begin{array}{c}\text { No } \\
\text { taking } \\
\text { chloramphenicol }\end{array}$ \\
\hline Drop retared toxic and alkergic conjunctivitis & 40 & 26 \\
\hline Initis & 17 & 10 \\
\hline Comeal abrasions and forcign bodies & 14 & 9 \\
\hline Proved infective conjunctivitis & 11 & 7 \\
\hline Bkepharitis, chabzions, and stres & 10 & 5 \\
\hline Episcteritis & 10 & 7 \\
\hline Dendritic ukers & 8 & 6 \\
\hline Cormeal ukers and abscesses & 7 & 5 \\
\hline Allergictatopic conjunctivitis & 5 & I \\
\hline Dry eves & 5 & 3 \\
\hline Others & 18 & 13 \\
\hline Total & 145 & 92 \\
\hline
\end{tabular}

